\title{
ONDE NÃO ESTÁ WALY SALOMÃO?
}

\section{SALOMÃO, WALY. POESIA TOTAL. SÃO PAULO: COMPANHIA DAS LETRAS, 2014. 549 P.}

Rafael Fava Belúzio*

Após as recentes publicações de Toda poesia, de Paulo Leminski, e de Poética, de Ana Cristina César, a editora Companhia das Letras lança Poesia Total, de Waly Salomão. Assim está sendo revisto o panorama da Literatura Brasileira Marginal: Leminski, Ana C. e Sailormoon, na verdade, parecem marginais aos marginais, estrangeiros aos estranhos, habitantes do indecidível, cultivadores de limiares, entre-lugares, sínteses. Não redutíveis à poesia rasteira e rápida apresentada por parte dos poetas marginais, os três escritores, juntos, mostram como era, ontem, heterogênea a coletânea 26 poetas hoje, de Heloísa Buarque de Hollanda. Mais próximo de Paulo Leminski e de Ana Cristina César, Waly Salomão - baiano nascido em 1943 e falecido em 2003 - desenvolve uma poética que busca a totalidade, não sendo gratuito o título dado à reunião dos versos do autor (nem a
* favabeluzio@yahoo.com.br

Doutorando do Programa de Pós-Graduação em Estudos Literários da Faculdade de Letras da UFMG.

impossível fragmentação em parágrafos, nem o gosto por frases alongadas, pequenas totalizações desta resenha que se pergunta onde não está Waly Salomão). Seguindo essa via, Poesia total agrupa sete ou oito livros e "Mais algumas canções”, textos publicados entre 1972 e $2004 .{ }^{1}$ Ao longo das produções, é possível vislumbrar a busca pelo todo, lembrando a poesia universal progressiva, de Friedrich Schlegel ${ }^{2}$ : tanto no escritor alemão quanto no baiano está a mescla de gêneros textuais, a fusão de poesia e prosa, de criação e autocrítica. Desde a prosa poética de Me segura qu'eu vou dar um troço (1972) há frases assim: "O texto como progressão de uma leitura intransitiva”. ${ }^{3}$ Há mesmo muito de romântico nesse livro que apresenta um sujeito lírico buscando "As tábuas da lei do meu próprio coração"4 e dono de um "peito sangrando das almas românticas. tenho os amores
1. A oscilação entre sete ou oito livros se deve ao fato de Poemas de Armarinho de miudezas e Hélio Oiticica: Qual é o parangolé estarem agrupados sob o mesmo rótulo. Nisso inidem questões ligadas ao projeto editorial.

2. Cf. SCHLEGEL $O$ dialeto dos fragmentos, p. 64-65.

3. SALOMÃO. Poesia total, p. 23.

4. SALOMÃO. Poesia total, p. 23 
5. SALOMÃo. Poesia total, p. 62.

6. SALOMÃo. Poesia total, p. 85.

7. SALOMÃO. Poesia total, p. 46.

8. SALOMÃO. Poesia total, p. 47.

9. SALOMÃo. Poesia total, p. 91.

10. SALOMÃO. Poesia total, p. 27.

11. SALOMÃO. Poesia total, p. 112.

12. SALOMÃO. Poesia total, p. 115.

13. SALOMÃO. Poesia total, p. 123. fracassados das almas românticas das raças doentias" . ${ }^{5}$ Possui também o peito ligado às tradições das Vanguardas Europeias (como o Surrealismo, que procura "criar condições pra que o delírio seja medida do universo" , o Futurismo, de palavras atomizadas, e o Dadaísmo, a ditar "Morte às linguagens existentes") e da dialética da malandragem ("sou safado o cara no Brasil não sobrevive se não for malandro" ${ }^{8}$ ), bem como está próximo de Ana Cristina César (ao produzir páginas de diários e "Fingir praticar a literatura de expressão pessoal") e de Paulo Leminski (sobretudo de algumas experiências verborrágicas do Catatau - apesar do cosmopolita curitibano ter conseguido mais com menos, em particular nos haicais - e devido ao sujeito lírico de Salomão - talvez expressando as vivências do autor, que escreveu Me segura qu'eu vou da um troço durante uma "estadia" no Carandiru - "ter sido encontrado com uma porção de erva denominada 'maconha"'10). Em liberdade, em 1983 saiu Gigolô de bibelôs, obra que continua "Sempre tendente a ser outra coisa. Carente de ser mais", ${ }^{11}$ pois, como diz o sujeito poético, "tudo sentir total é chave de ouro do meu jogo", "12 "Tenho fome de me tornar em tudo que não sou" ${ }^{13}$ Com esse livro, e continuando na esfera da produção de "si mesmo", Waly Salomão se insere na tradição da despersonalização do sujeito justamente na medida em que gera uma hiper-heteropersonalização de si: o eu lírico tanto mais é a si quanto mais se torna a soma de outros. Graficamente, essa busca pelo total se faz via junção de recursos visuais e sonoros, soma de publicidade e música popular, pontuações e cores e formas de caligrafia e de usos de páginas e métricas e versos livres. Não por acaso, são muitas as letras de canções presentes no livro de 1983, como "Vapor barato", "Mal secreto" e "Talismã"; isso talvez sugira o fato de, cotidianamente, Waly Salomão ser muito cantarolado, em função de intérpretes como Gal Costa e Caetano Veloso, mas nem tão conhecido como poeta. Após os Gigolôs de bibelôs, na parte seguinte - Poemas de armarinho de miudezas (1983) e Hélio Oiticica: qual é o parangolé? (1986), presente em Poesia total - a opção escolhida pelos editores faz haver uma perda significativa, como se compreende observando a nota de abertura: "Armarinho de miudezas [...] é um livro híbrido e de difícil classificação, que reúne textos ensaísticos e poéticos. Optamos por reproduzir aqui apenas os textos em verso que aparecem ao longo do livro". ${ }^{14}$ Pensando na poética da totalidade, desenvolvida por Waly Salomão, a retirada de partes do livro (sub)trai a tentativa de dissolução dos gêneros, embora nos versos restantes do poeta ainda seja possível vislumbrar, por exemplo, a "Marécheia de fofocas por todos os lados", "Bahia de todas as trevas”. ${ }^{16}$ Um pouco depois, Algaravias: câmara de ecos, de 1996, não passou pelo mesmo problema de subtração editorial. Ao contrário, continua se somando à expansão do poeta: "Agora, entre o meu ser e o alheio/ a linha de fronteira se rompeu". ${ }^{17}$ $\mathrm{E}$ - para abusar, aqui, dessa palavra aditiva -, mais ou menos
14. Poesia total, p. 198. (Nota do editor).

15. SALOMÃO. Poesia total, p. 202.

16. SALOMÃO. Poesia total, p. 202.

17. SALOMÃO. Poesia total, p. 219.

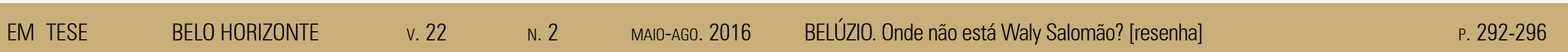


18. SALOMÃO. Poesia total, p. 220.

19. SALOMÃo. Poesia total, p. 229.

20. SALOMÃO. Poesia total, p. 247.

21. SALOMÃO. Poesia total, p. 262.

22. SALOMÃO. Poesia total, p. 296.

23. SALOMÃO. Poesia total, p. 304.

24. SALOMÃO. Poesia total, p. 321. seguindo a perspectiva de Ana Cristina César, aparece uma crítica à poesia cabralina do menos, ou mais precisamente aos seguidores dessa poesia, aos seguidores que não conseguiram um "seco,/ rígido, severo" que "esplende em flor", mas apenas "brevidade-não concisão". ${ }^{18} \mathrm{Ou}$ como foi escrito na letra cantada por Adriana Calcanhoto: "o prédio, pedra e cal, esvoaça/ como um leve papel solto à mercê do vento", ${ }^{19}$ e está sempre solta à mercê do vento a reescrita em Salomão, porque é comum haver poema já musicado e reescrito pelo poeta, pois a expansão não pode parar... "a imaginação voa". O eu lírico se apresenta como "Proteu: deus marinho da mitologia grega, com poder de se metamorfosear à vontade; deus polimorfo" . ${ }^{21} \mathrm{Na}$ forma seguinte, o livro Lábia, de 1998 , nesse momento pós-tudo em que "já não me habita mais nenhuma utopia", ${ }^{22}$ o poeta continua se dizendo "Novíssimo Proteu" - o que, a essa altura, já não parece muita novidade: "não sou uno, monolítico, inteiriço/ [...] Sou volátil, diáfano, evasivo”. ${ }^{33}$ Continuam também as inovações gráficas, sendo elas, em tal turno, certa diluição das supostas rupturas concretistas/neoconcretistas, e, possivelmente, levando o leitor a duvidar que o poeta continuaria fazendo novas todas as coisas, ou, ao menos, "Para cada poema, variações da ars poetica” ${ }^{24}$ Apesar de ser possível questionar os limites de um metamorfoseador que não muda a constante de metamorfoses - tornando velha conhecida de si a fórmula do make it new -, ao sair, em 2000, Tarifa de embarque, Waly Salomão publica o poema "Remix 'século XX", ${ }^{25}$ também musicado por Adriana Calcanhoto, espécie de composto formado por palavras atomizadas, expressivas ao longo do século XX e da poética de Salomão. De todo modo, com o passar dos livros, os recursos do escritor vão, de certa maneira, se repetindo, deixando mais claro o seu lugar e fazendo ver, na contramão, onde não está Waly. Até mesmo no último livro, Pescados vivos (2004), a resposta parece clara como a ausência dela: "Eu estou ausente porém no fundo desta ausência/ Existe a espera de mim mesmo", ${ }^{26}$ ainda mais expressivos estes dois versos se notados que foram escritos pelo chileno Vicente Huidobro e "somente" traduzidos por Waly Salomão. A parte "Mais algumas canções", ao final do livro, traz letras musicadas por nomes como Lulu Santos e Gilberto Gil. Entretanto, se nas últimas obras havia certo cansaço da fórmula totalizadora, a Poesia total, no "Apêndice", ganha novo fôlego: uma fortuna crítica de quase cem páginas consegue mostrar, se não tudo, muito da poética de Waly. Indicando a pedra de toque de Salomão, aparecem, ecoando numa vertigem de lista em progressão temporal, textos do próprio poeta, assim considerações de Francisco Alvim - "ficção híbrida, pois contém em si os planos da poesia e do ensaio", ${ }^{27}$ "a ambiguidade é um dos dados fundamentais do livro"28 -, Armando Freitas Filho - reconhecedor de que "O livro de Waly Salomão não pede uma resenha costumeira" ${ }^{29}$, e de que "Waly Salomão se multiplica, simultâneo, minucioso e
25. SALOMÃO. Poesia total, p. 387390.

26. SALOMÃO. Poesia total, p. 440 .

27. ALVIM. Vale a pena falar de novo, p. 467.

28. ALVIM. Vale a pena falar de novo, p. 468.

29. FREITAS FILHO. Gigolô \& bibelôs: a poesia começa quando você chega, p. 472.

EM TESE BELO HORIZONTE $\quad$ v. $22 \quad$ N. 2 MAI0-Ago. $2016 \quad$ BELÚZIO. Onde não está Waly Salomão? [resenha] $\quad$ P. 292-296


30. FREITAS FILHO. Gigolô đ bibelôs: a poesia começa quando você chega, p. 472.

31. RISÉRIO. Qwalyssignos, p. 475.

32. ARRIGUCCI JR. Algaravias, p. 476.

33. RODRIGUES, Waly Salomão e a lógica da pessoa, p. 479.

34. WISNIK. Lábia, p. 483.

35. BUENO. Lábia, de Waly Salomão, p. 485 .

36. HOLLANDA. Gigolô de bibelôs p. 488.

37. GALVÃO. Tarifa de embarque, $p$. 491.

38. CÍCERO. A falange de máscaras de Waly Salomão, p. 492.

39. OITICICA. Héliotape, p. 516.

40. PERRONE-MOISÉS. Pescados vivos, 519.

41. SANTIAGO. Waly: entre Drummond e Oiticica, p. 525

42. ZULAR. As algaravias de Waly Salomão, p. 527.

43. LEMINSKI. Poesia limite, p. 470.

44. LEMINSKI. Poesia limite, p. 471. memorável”30 -, Antônio Risério - "Estrada do Excesso"31 Davi Arrigucci Jr. - "mar sem margem"32 -, Antonio Medina Rodrigues - "supressão das fronteiras entre o eu e o outro" ${ }^{33}$ -, José Miguel Wisnik - "seu teatro instantaneísta é um arrastão que põe tudo à volta em um ato" ${ }^{34}$-, Alexei Bueno "O primeiro encontro e o primeiro espanto do leitor é com o duplo caráter pessoal do poeta [...], um vitalista e outro verbal, sem que se saiba onde um acaba e o outro começa"3. -, Heloisa Buarque de Hollanda - "presença de um referencial explicitamente erudito que se disfarça impregnando uma poética víscera, anárquica e politicamente interpelativa"36 -, Walnice Nogueira Galvão - "assomo de libertação que tem nele a sina do nomadismo" ${ }^{37}$-, Antonio Cícero "por trás de uma fragmentariedade ostensiva, uma identidade fundamental de preocupações [...], uma identidade na anti-identidade" ${ }^{38}$-, Hélio Oiticica - "esse negócio de quando você considera o fim uma coisa e de repente você continua, acrescenta mais um?" ${ }^{9}$-, Leyla Perrone-Moisés - "nenhuma etiqueta colava no Waly; ele se mexia demais"40 -, Silviano Santiago - "detestava comedimentos" ${ }^{41}$-, Roberto Zular - "vozes que se chocam e se contradizem num movimento contínuo de construção e desconstrução". ${ }^{42}$ Dessa progressão fragmentada de vozes, convém destacar a presença de Paulo Leminski - "livro de exageros", 43 "hipérbole". ${ }^{44}$ No apêndice do autor de uma poética total, o autor de uma poética sintética: o aparecimento de Leminski ajuda a entrelaçar - acoplada à ausente, embora de sombra presente, tão ao gosto dela, Ana Cristina César - o que chamei de marginais entre os marginais; mostra a possibilidade de influência mútua entre eles e faz esta resenha voltar ao seu começo, se não para se tornar total, oroboro, ao menos para se fechar enquanto coisa em si e aberta ao outro que é aberto aos muitos outros e dificulta responder a pergunta - talvez retórica, certamente paródia pop - inicial: onde não está Waly Salomão?

\section{REFERÊNCIAS}

ALVIM, Francisco. Vale a pena falar de novo. In: SALOMÃO, Waly. Poesia total. São Paulo: Companhia das Letras, 2014. p. 467 469.

ARRIGUCCI JR. Davi. Algaravias. In: SALOMÃO, Waly. Poesia total. São Paulo: Companhia das Letras, 2014. p. 476-477.

BUENO, Alexei. Lábia, de Waly Salomão. In: SALOMÃO, Waly. Poesia total. São Paulo: Companhia das Letras, 2014. p. 485487.

CÉSAR, Ana Cristina. Poética. São Paulo: Companhia das Letras, 2013

CíCERO, Antonio. A falange de máscaras de Waly Salomão In: SALOMÃO, Waly. Poesia total. São Paulo: Companhia das Letras, 2014. p. 492-514 
FREITAS FILHO, Armando. Gigolô \& bibelôs: a poesia começa quando você chega. In: SALOMÃO, Waly. Poesia total. São Paulo: Companhia das Letras, 2014. p. 472-473.

GALVÃO, Walnice Nogueira. Tarifa de embarque. In: SALOMÃO Waly. Poesia total. São Paulo: Companhia das Letras, 2014. p. 490-491.

HOLLANDA, Heloisa Buarque de (Org.). 26 poetas hoje. Rio de Janeiro: Aeroplano, 2007.

HOLLANDA, Heloisa Buarque de. Gigolô de bibelôs. In SALOMÃO, Waly. Poesia total. São Paulo: Companhia das Letras, 2014. p. 488-489.

LEMINSKI, Paulo. Toda poesia. São Paulo: Companhia das Letras, 2013

LEMINSKI, Paulo Poesia limite, In: SALOMÃO, Waly Poesia total São Paulo: Companhia das Letras, 2014 p. 470-471.

LEMINSKI, Paulo. Catatau. Curitiba: Ed. do Autor, 1975

OITICICA, Hélio. Héliotape. In: SALOMÃO, Waly. Poesia total. São Paulo: Companhia das Letras, 2014. p. 515-518.

PERRONE-MOISÉS, Leyla. Pescados vivos. In: SALOMÃO, Waly. Poesia total. São Paulo: Companhia das Letras, 2014 p. 519520

RISÉRIO, Antonio. Owalyssignos. In: SALOMÃO, Waly. Poesia total. São Paulo: Companhia das Letras, 2014. p. 474-475.
RODRIGUES, Antonio Medina. Waly Salomão e a lógica da pessoa. In: SALOMÃO, Waly. Poesia total. São Paulo: Companhia das Letras, 2014. p. 478-482.

SALOMÃO, Waly. Poesia total. São Paulo: Companhia das Letras, 2014

SANTIAGO, Silviano. Waly: entre Drummond e Oiticica. In SALOMÃO, Waly. Poesia total. São Paulo: Companhia das Letras, 2014. p. 521-525.

SCHLEGEL, Friedrich. 0 dialeto dos fragmentos. São Paulo: Iluminuras, 1997

WISNIK, José Miguel. Lábia. In: SALOMÃO, Waly. Poesia total São Paulo: Companhia das Letras, 2014. p. 483-484.

ZULAR, Roberto. As algaravias de Waly Salomão. In: SALOMÃO, Waly. Poesia total São Paulo: Companhia das Letras, 2014. p. $526-541$ 